\title{
AMAMENTAÇÃo E SUAS PRERROGATIVAS PARA A SAÚDE DO BINÔMIO MÃE-FILHO
}

\author{
Daniele Barreto M. Gomes ${ }^{3}$, Carolina M. Santos ${ }^{2} \&$ Roberta Lastorina Rios ${ }^{1,2}$
}

(1) Professora orientadora do curso de enfermagem ISECENSA- Institutos Superiores de Ensino do CENSA, Rua Salvador Correa, 139, Centro,

Campos dos Goytacazes - RJ, Brasil; (2) Pesquisadores do Laboratório de Estudos em Saúde Pública - (NUPENSP/ISECENSA); (3) Acadêmica do

curso de Enfermagem ISECENSA.

A amamentação é uma prática milenar que pode ser fonte única de sustento para a criança até o sexto mês, acrescido de outros alimentos a partir dessa idade, produzindo benefícios nutricionais, imunológicos, cognitivos, sociais e econômicos que são melhor usufruídos quando ampliados até os dois anos de idade. Embora a amamentação seja uma função biológica natural, pode sofrer influência de diversos fatores, fazendo-se necessário o compromisso de todas as partes envolvidas e conhecimento técnico-científico dos profissionais de saúde no incentivo e apoio a esta prática. Nesse contexto, os profissionais Enfermeiros estarão atuantes tanto no pré-natal quanto no puerpério, apoiando; identificando possíveis impedimentos e complicações; orientando; prescrevendo condutas para prevenir ou resolver patologias já existentes. Sendo assim, os objetivos dessa pesquisa são: identificar os proveitos da aleitação para o binômio mãe-filho e discutir o papel do enfermeiro no incentivo e apoio à amamentação. Este estudo foi realizado através do método de revisão integrativa da literatura, com análise de 20 publicações científicas, disponíveis em base de dados online SCIELO E BVS, publicados nos últimos 10 anos (2008-2018). Utilizou-se os seguintes DeCS: aleitamento materno, enfermagem, saúde da mulher, desmame precoce. De acordo com os resultados das publicações analisadas, as crianças que recebem o leite materno, possuem melhor desenvolvimento e apresentam relativo aumento de inteligência em relação às crianças não amamentadas. Também foi constatado que previne alterações ortodônticas, de fala e diminui a incidência de cáries. Além disso, reduz a mortalidade infantil ocasionada por infecções respiratórias graves e infecções gastrointestinais, motivadas pela abertura de fontes de aleitamento que não seja o leite humano antes do quarto mês de vida, gerando também benefícios sociais pela diminuição do número de atendimentos médicos, hospitalizações e medicamentos, além de diminuir a falta dos pais no trabalho. Fortalece os laços afetivos entre mãe e filho, favorecendo a regressão física materna antecedente à gestação, limita o sangramento no puerpério pela contração uterina estimulada pela ação da ocitocina, prevenindo assim o risco de anemia e auxiliando o útero ao retorno do seu volume normal. Conclui-se que a falta de orientação profissional adequada e a falta de incentivo, podem levar ao desmame precoce, e, neste contexto o Enfermeiro desempenha papel de fundamental relevância, especialmente nas orientações à mulher, mostrando a existência de momentos oportunos de educação relacionados à amamentação, comprometendo-se não apenas em repassar conhecimentos científicos, mas, principalmente, pela arte e sensibilidade que pode desenvolver no outro, sentimentos e vontades que induzem ao aleitamento materno.

Palavras-chave: amamentação, enfermagem, saúde da mulher. 